\title{
Percutaneous Management of Thrombosed Dialysis Access Grafts
}

\author{
Thuong Van Ha, M.D. ${ }^{1}$
}

\section{ABSTRACT}

This article reviews current concepts in the percutaneous management of thrombosed polytetrafluoroethylene (PTFE) dialysis access grafts. The maintenance of dialysis access grafts remains a challenging task. Graft surveillance is critical in the prevention of graft thrombosis to prolong graft survival. Once a graft is thrombosed, surgical and percutaneous options are available for restoration of flow. There has been an evolution in the percutaneous treatment of thrombosed dialysis access grafts during the last 20 years, with refinement of pharmacomechanical techniques, allowing for safe and efficacious restoration of flow in thrombosed grafts. There has been emergence of alternative thrombolytic agents to urokinase, which was withdrawn from the United States in late 1998 and recently reintroduced. These alternative thrombolytic agents have similar outcomes compared with urokinase, with the additional advantage of being less expensive. In addition, several mechanical devices, which were popular briefly when urokinase was unavailable, are available currently for use within grafts, with similar success, although their prices have limited widespread use.

KEYWORDS: Grafts, hemodialysis, thrombosis, grafts, thrombolysis, fibrinolytics

Objectives: Upon completion of this article, the reader should be able to (1) summarize the different techniques used in declotting thrombosed dialysis access grafts, (2) list chemical agents used in declotting, and (3) describe the mechanical devices available for declotting.

Accreditation: Tufts University School of Medicine (TUSM) is accredited by the Accreditation Council for Continuing Medical Education to provide continuing medical education for physicians.

Credit: TUSM designates this educational activity for a maximum of 1 Category 1 credit toward the AMA Physicians Recognition Award. Each physician should claim only those credits that he/she actually spent in the activity.

In the United States, polytetrafluoroethylene (PTFE) grafts are widely used for vascular access despite the superiority of native arteriovenous (AV) fistulae compared with PTFE grafts, in terms of patency and complication rates. ${ }^{1-4}$ One advantage the PTFE grafts have over native AV fistulae is the ability to be used for dialysis within 30 days vs. the 60- to 90-day waiting period for native fistulae to mature. Although the focus of this article is in the percutaneous management of thrombosed PTFE grafts, it must be emphasized that a surveillance program to prevent graft thrombosis is important in the maintenance of vascular access in the

Interventional Radiology in Dialysis; Editor in Chief, Peter R. Mueller, M.D.; Guest Editor, Brian Funaki, M.D. Seminars in Interventional Radiology, volume 21, number 2, 2004. Address for correspondence and reprint requests: Thuong Van Ha, M.D., Department of Radiology, Section of Vascular and Interventional Radiology, The University of Chicago, 5841 South Maryland Avenue, Chicago, IL 60637. E-mail: tgvanha@radiology.bsd.uchicago.edu. ${ }^{1}$ Radiologist, Department of Radiology Section of Vascular and Interventional Radiology, The University of Chicago, Chicago, Illinois. Copyright (C) 2004 by Thieme Medical Publishers, Inc., 333 Seventh Avenue, New York, NY 10001, USA. Tel: +1(212) 584-4662. 0739-9529,p;2004,21,02,077,081,ftx,en;sir00234x. 
patients with chronic renal failure. When significant stenoses are treated prior to graft thrombosis, graft survival is improved and the incidence of graft thrombosis decreases. ${ }^{5-7}$ In addition, it is in the best interest of the patients, when possible, to develop a dialysis access team consisting of nephrologists, interventionalists, and surgeons for the monitoring and management of these patients' vascular access. ${ }^{8}$ At minimum, there must be frequent communication among the healthcare workers who together have the responsibility of management of venous access for the dialysis patients.

When a PTFE graft thromboses, three treatment options exist. First, there is surgical thrombectomy. Second, the thrombosed graft can be percutaneously declotted. Third, the graft can be abandoned in favor of another site or another vascular access technique such as catheter dialysis. Surgical thrombectomy remains a viable and common technique to treat thrombosed PTFE grafts. Simple surgical thrombectomy has poor long-term outcome because inciting lesions are left untreated. Surgical thrombectomies with access revisions, including patch angioplasty of venous anastomosis, jump grafts involving moving the venous anastomosis more centrally, and excision and replacement of the damaged portion of PTFE grafts, have more favorable long-term outcomes. ${ }^{9,10}$ One disadvantage of surgical revision is the loss of precious native vein in the case of the transposition jump graft. The Dialysis Outcomes Quality Initiative (DOQI) Work Group recommends a primary patency rate of $50 \%$ at 6 months and $40 \%$ at 1 year for surgically revised thrombosed grafts. ${ }^{1,2}$ The expected primary patency rate for percutaneous treatment of thrombosed PTFE grafts at 3 months is $40 \%$. This is acceptable because percutaneous treatment spares the native veins. The method of treatment used depends on the referral pattern, the availability of physicians, and also the patient's preference. At our institution, a patient with a thrombosed PTFE graft is referred to interventional radiology for percutaneous treatment, unless the patient prefers surgical thrombectomy. If the percutaneous treatment is unsuccessful, the patient proceeds to surgical thrombectomy and revision. A dialysis catheter is placed only if the patient is in need of immediate dialysis. Patients are referred to surgery if their grafts rethrombose within a short period (twice in 2 weeks at our institution), or if there are elastic lesions or long segment stenoses that do not respond to initial percutaneous dilation. There appears to be no financial advantage of using either surgical or percutaneous techniques in the treatment of thrombosed grafts. ${ }^{11}$

Percutaneous treatment of thrombosed PTFE grafts has evolved during the last decade. The techniques involve use of thrombolytics, mechanical devices, and balloons for thrombectomy. The technique used depends largely on physician preference. However, in certain cases, specific needs dictate which technique is used. In addition, cost of devices or drugs can be a major determinant in choosing a particular technique.

\section{MECHANICAL DEVICES}

Currently, several devices are approved by the U.S. Food and Drug Administration for the thrombectomy of dialysis grafts. They are divided into devices with wall contact and without wall contact. All have been shown to be efficacious, with similar results as surgical thrombectomy and pharmacomechanical thrombolysis. However, the expense of these mechanical devices has limited their use and universal acceptance. In cases of large clot burden, they might be useful adjuncts to debulk clot prior to other therapy. When thrombolytics are contraindicated (such as in patients with recent surgery, gastrointestinal hemorrhage, hemoptysis, or intracranial tumors), these devices can occasionally be used but are often limited because optimal results are achieved with concomitant heparinization. Brief discussions of the available devices follow.

The Amplatz mechanical thrombectomy device (ATD, Microvena, White Bear Lake, MN) uses an impeller to create a vortex, which then pulverizes the clots to small particles with sizes less than $13 \mu \mathrm{m}$. These particles are expelled. In a randomized study comparing the ATD and surgical thrombectomy, the success rate was 89 vs. $83 \%$, respectively. ${ }^{12}$ However, the 30 -day patency rate was $47 \%$ for the ATD vs. $77 \%$ for surgery. The 30-day secondary patency rate for the ATD was 68 vs. $77 \%$ for surgery. Another study compared the use of the ATD to the modified pulse-spray pharmacomechanical thrombolysis technique in the treatment of thrombosed access grafts. ${ }^{13}$ Although both techniques were similarly successful in the restoration of flow, with patency rates not statistically significant, there was higher rate of local complications (16 vs. 6\%) with the ATD, including four cases of arterial emboli, two of which were symptomatic. There were three cases of pseudointimal dissection of the graft.

The AngioJet device (Possis Medical, Minneapolis, MN) uses the Bernoulli effect to macerate and aspirate clots from the grafts. The device is used over the wire. In a randomized trial comparing the treatment of thrombosed dialysis grafts with the AngioJet vs. surgical thrombectomy, the success rates of restoration of flow were similar for the two techniques with patency rates favoring the surgical group. ${ }^{14}$ The 90 -day patency rate of the AngioJet group was 15\%, significantly lower than standards set by the Dialysis Outcomes Quality Initiative Guidelines. ${ }^{1,2}$ The cost of the pump set has dissuaded some from using the device.

The Oasis thrombectomy device (Boston Scientific, Natick, MA) uses a high-pressure system to create the Venturi effect to macerate clots that are moved to a collection bag. In a preliminary study, we compared 
the use of the Oasis device with the use of the pulsespray pharmacomechanical technique using recombinant tissue-type plasminogen activator (rt-PA). ${ }^{15}$ The success rates of restoration of flow through the thrombosed grafts were similar ( $94 \%$ for both groups). However, there was slightly higher patency rate with the use of the pulse-spray technique (61 vs. $51 \%$ at 60 days).

A few other devices are available. ${ }^{16-19}$ The Cragg and Castaneda Brushes (MicroTherapeutics, San Clemente, CA) use rotating soft nylon brushes to macerate clots. The brush operates by a hand-held, battery-driven device. The Casteneda Brush is reviewed in a separate article in this issue. The Gelbfish EndoVac (NeoVascular Technologies, Brooklyn, NY) uses suction with saline irrigation to remove clots from grafts. The Hydrolyser Catheter (Cordis Endovascular, Warren, $\mathrm{NJ}$ ) uses an over-the-wire, high-pressure system to macerate clots, which are then removed through the exhaust system into a collection bag. The Trerotola percutaneous thrombectomy device (Arrow International, Reading, PA) is a self-expanding cage that macerates clots by rotation from 3000 to $4500 \mathrm{rpm}$. The macerated clots are removed by aspiration through the sheath.

\section{PHARMACOMECHANICAL THROMBOLYSIS}

The use of streptokinase was described in the early 1980s for treatment of thrombosed grafts. ${ }^{20}$ However, its use was limited by bleeding complications and allergic reactions. Urokinase (Abbott Laboratories, North Chicago, IL) drip infusion was technically successful but was time consuming, costly, and had similar local bleeding complications as streptokinase. ${ }^{21,22}$ When urokinase became unavailable in the United States, alteplase (rt-PA, Genentech, South San Francisco, CA) and reteplase (recombinant plasminogen activator [r-PA], Centocor, Malvern, PA) became the thrombolytics of choice. Urokinase has been reintroduced recently in the U.S. market. Currently, protracted infusion thrombolysis is seldom used to treat thrombosed grafts. The use of adjunctive mechanical components has allowed for faster restoration of flow through thrombosed PTFE grafts with minimal complications. The lacing and maceration technique described in 1989 used injection of concentrated urokinase, rotation of catheters, and aspiration of clots to bring the infusion time down to 86 minutes. $^{23}$ The modified lacing and maceration technique described by Bookstein et $\mathrm{al}^{24}$ used two crossing catheters and pulse-spray of concentrated urokinase into the thrombus. The mean infusion time for this technique was 49 minutes. Valji et $\mathrm{al}^{25}$ improved on the pulse-spray technique by the concomitant use of heparin, balloon thrombectomies of the clots, and arterial plugs, with reduction of mean infusion time to 23 minutes. The primary patency rate for this technique was $70 \%$ at 30 days and $50 \%$ at 90 days.

Another popular technique, lyse-and-wait, was described by Cynamon. ${ }^{26}$ Through a catheter placed near the arterial anastomosis, directed toward the venous limb, a solution of 250,000 $\mathrm{U}$ of urokinase mixed with $5000 \mathrm{U}$ of heparin was injected into the graft with manual compression of the arterial and venous anastomoses. This can be performed while the patient is in a holding area. After waiting for 45 minutes, the patient is brought into the interventional suite and the arterial plug thrombectomy is performed with a compliant balloon catheter. The venous anastomosis and venous outflow are then evaluated.

At the University of Chicago, we use the modified pulse-spray technique described by Valji et $a 1,{ }^{25}$ with some changes. First, we place a catheter into the venous limb and evaluate the central venous outflow. Any central stenosis can be treated at this time. If central lesions cannot be treated, we generally abandon the procedure at this point. Between 3000 and $8000 \mathrm{U}$ of heparin is given intravenously. Lytic agent is then infused into the graft. Another puncture is made in a cross-configuration fashion directed toward the arterial limb and the arterial anastomosis is crossed. An inflow arteriogram is performed. The arterial plug is pulled into the graft with a compliant balloon. The clots are then macerated with the compliant arterial-directed balloon and also the venous-directed balloon. Once thrombolysis is complete, and flow in the AV graft is restored, outflow venogram is performed. Prior to restoration of flow, it would be difficult to assess the venous anastomosis and venous outflow because of the nondistended vein and presence of clots. Outflow stenoses are treated with angioplasty and if necessary, stenting.

\section{THROMBOLYTIC AGENTS}

Urokinase was the agent of choice for peripheral thrombolysis and AV graft declotting prior to its withdrawal from the U.S. market in late 1998. As mentioned, it was the agent used for drip infusion for treatment of thrombosed grafts, in the original description of pulse-spray technique as well as in the modified pulse-spray pharmacomechanical technique. ${ }^{22-26}$ Urokinase was recently reintroduced and is available in $250,000-\mathrm{U}$ vials. In the past, we used 500,000 $\mathrm{U}$ reconstituted in $10 \mathrm{~mL}$ normal saline solution for a graft declot. Occasionally, we used up to 1 million $U$ in patients with large clot burdens. When urokinase was unavailable, two other agents became popular in treating thrombosed grafts.

rt-PA is a recombinant form of mammalianderived serine protease, which belongs to a class of drugs known as plasminogen activators. Naturally occurring tissue plasminogen activator is secreted by the vascular endothelium, and is critical in maintaining a balance 
between hemostasis and fibrinolysis. ${ }^{27}$ The free circulating half-life of alteplase is $\sim 5$ minutes. The rt-PA molecules are made up of several domains, including a kringle-1 domain, associated with hepatic receptor binding, and a kringle-2 domain, associated with low affinity-fibrin binding. The rt-PA molecule also contains a finger domain associated with high fibrin binding and an epidermal growth factor domain, associated with hepatic receptor binding. The deletion of the finger, EFG, and kringle-1 domain from the rt-PA molecule results in the r-PA molecule, with longer half-life, less fibrin affinity, and high fibrin specificity. ${ }^{28}$ It should be noted that use of urokinase, rt-PA, and r-PA in the treatment of thrombosed dialysis access grafts is off-label.

In our preliminary experience, ${ }^{29}$ we performed a retrospective review of 53 consecutive thrombosed PTFE arm grafts treated with either alteplase $(n=32)$ or reteplase $(n=21)$. The alteplase dose was 1,2 , or $3 \mathrm{mg}$. The reteplase dose used was $0.5,1.0$, or $2.0 \mathrm{U}$. The success rate for restoration of flow in the alteplase group was $92 \%$ and in the reteplase group was 95\%. There was a higher primary patency rate with the reteplase group at 30 days (79 vs. 68\% for alteplase) but the 180-day patency rates for the two agents were similar (30 vs. $32 \%$ ). No bleeding complications were observed in these patients despite the concomitant use of heparin.

Other studies show, overall, adequate results with these agents, although a consensus on dose remains elusive. A study using $2 \mathrm{mg}$ of alteplase in conjunction with $3000 \mathrm{U}$ of heparin showed an $88 \%$ success rate. ${ }^{30}$ Patency rates were $57 \%$ at 30 days and $50 \%$ at both 90 and 180 days. Another study of alteplase in the lyse-andwait technique as compared with mechanical thrombolysis showed a patency rate of $65 \%$ at 3 months. ${ }^{31}$ The alteplase dose was $4 \mathrm{mg}$. There were seven bleeding episodes in six patients among the 40 patients randomized to the alteplase arm. One patient required hospitalization and two patients needed additional therapy. A recent pilot study enrolled 17 patients for declotting using the pulse-spray technique with alteplase. ${ }^{32} \mathrm{~Pa}^{-}$ tients received an average of $2 \mathrm{mg}$ of alteplase. The success rate was $94 \%$ and patency rates were $71 \%$ at 30 days and $47 \%$ at 90 days. No complications were observed in this study. A study of reteplase in the treatment of thrombosed grafts showed $92 \%$ technical success rate and patency rates of $34 \%$ at 180 days, without associated major complications. ${ }^{33}$

Currently, we use rt-PA because it is available through our hospital formulary and it is relatively inexpensive. rt-PA is available in 2-mg vials, which are approved for catheter clearance. We typically use $4 \mathrm{mg}$ for each declotting procedure. Despite this dosage, we have rarely encountered major bleeding complications during or after the procedures in the last 5 years.

\section{SUMMARY}

The percutaneous treatment of thrombosed PTFE grafts has evolved during the last 20 years. Faster, more costeffective methods and longer patency rates remain the goals of any new technique. Declotting has evolved from the drip infusions of 20 hours duration to the current pharmacomechanical thrombolysis or lyse-andwait techniques using a lytic agent, heparin, and balloon catheters. A routine graft declot in our department usually is complete in 30 to 45 minutes. With the temporary suspension of urokinase from the market in 1998, mechanical devices briefly became popular but because of cost, have not gained universal acceptance. We employ these devices only if there is a contraindication to use of fibrinolytics or in patients with large clot burdens that may benefit from debulking. The development of other fibrinolytics as declotting agents, mainly rt-PA and r-PA, also occurred during the period of time urokinase was withdrawn. These agents have shown similar success rates and patency rates as urokinase and are now widely used because they are much less expensive than urokinase. We have not found any significant differences among these agents in our clinical practice. Finally, with the advent of brachytherapy and drug-eluting stents, there is hope that patency rates for virgin or thrombosed grafts might be improved significantly.

\section{REFERENCES}

1. National Kidney Foundation. Dialysis Outcomes Quality Initiative (NFK-DOQI). Clinical practice guidelines for hemodialysis vascular access. Am J Kidney Dis 1997;30: 5154-5196

2. National Kidney Foundation. Dialysis Outcomes Quality Initiative (NFK-DOQI). Clinical practice guidelines for hemodialysis vascular access. Am J Kidney Dis 2001; 37(suppl 1):s137-s181

3. Chazan JA, London MR, Pono LM. Long-term survival of vascular accesses in a large chronic hemodialysis population. Nephron 1995;69:228-233

4. Jenkins AM, Buist TA, Glover SD. Medium-term follow-up of forty autogenous vein and forty polytetrafluoroethylene (Gore-Tex) grafts for vascular access. Surgery 1980;88:667672

5. Schwab SJ, Raymond JR, Saeed M, et al. Prevention of hemodialysis fistula thrombosis: early detection of venous stenoses. Kidney Int 1989;36:707-711

6. Roberts AB, Kahn MB, Bradford S, et al. Graft surveillance and angioplasty prolongs dialysis graft patency. J Am Coll Surg 1996;183:486-492

7. Martin LG, MacDonald MJ, Kikeri D, et al. Prophylactic angioplasty reduces thrombosis in virgin ePTFE arteriovenous dialysis grafts with greater than $50 \%$ stenosis: subset analysis of a prospectively randomized study. J Vasc Interv Radiol 1997;8:163-170

8. Pflederer TA, Darras FS, Welch K, et al. How to organize hemodialysis vascular access quality assurance efforts into a 
cohesive whole for better patient outcomes. Contemp Dial Nephrol 2000;1:18-21

9. Bone GE, Pomajzi MJ. Management of dialysis fistula thrombosis. Am J Surg 1979;138:901-906

10. Brotman DN, Fandos L, Faust GR, Dosher W, Cohen JR. Hemodialysis graft salvage. J Am Coll Surg 1994;178:431434

11. Vesely TM, Idso MC, Audrian J, Windus DW, Lowell JA. Thrombolysis versus surgical thrombectomy for the treatment of dialysis graft thrombosis: pilot study comparing cost. J Vasc Interv Radiol 1996;7:507-512

12. Uflacker R, Rajagopalan PR, Vujic I, Stutley JE. Treatment of thrombosed dialysis access grafts: randomized trial of surgical thrombectomy versus mechanical thrombectomy with the Amplatz device. J Vasc Interv Radiol 1996;7:185-192

13. Constantinos TS, Cooper SG, Schur I, Patel RI, Iqbal A, Walker S. Retrospective comparison of the Amplatz thrombectomy device with modified pulse-spray thrombolysis in the treatment of thrombosed hemodialysis access grafts. Radiology 1999;213:561-567

14. Vesely TM, Williams D, Weiss M, et al. Comparison of the AngioJet rheolytic catheter to surgical thrombectomy for the treatment of thrombosed hemodialysis grafts. J Vasc Interv Radiol 1999;10:1195-1205

15. Van Ha T, Kim R. Thrombolysis of dialysis access grafts with the Oasis device versus pulse-spray with rt-PA. J Vasc Interv Radiol 2001;12(suppl):s136-s137

16. Casteneda F, Cragg AH, Wyffels P, et al. New thrombolytic brush catheter in thrombosed polytetrafluoroethylene dialysis grafts: Preliminary animal study. J Vasc Interv Radiol 1995; 2:10

17. Gelbfish GA. Experience with a new suction thrombectomy device in clotted AV grafts. J Vasc Interv Radiol 1997;8:243 (Abst)

18. Bucker A, Schmitz-Rode T, Vorwark D, Gunter R. Comparative in vitro study of two percutaneous hydrodynamic thrombectomy systems. J Vasc Interv Radiol 1996;7: 445-449

19. Trerotola SO, Vesely TM, Lund GB, et al. Treatment of thrombosed hemodialysis access grafts: Arrow-Trerotola percutaneous device versus pulse-spray thrombolysis. Radiology 1998;206:403-414

20. Gray RJ. Percutaneous intervention for permanent hemodialysis access: a review. J Vasc Interv Radiol 1997;8:313-327
21. Schilling JJ, Eiser AR, Slifkin RF, et al. The role of thrombolysis in hemodialysis access occlusion. Am J Kidney Dis 1987;10:92-97

22. Summers B, Drazen K, Gomes A, et al. Urokinase therapy for thrombosed hemodialysis access grafts. Surg Gynecol Obstet 1993;176:534-538

23. Davis GB, Dowd CF, Bookstein JJ, et al. Thrombosed dialysis grafts: efficacy of intrathrombic deposition of concentrated urokinase, clot maceration and angioplasty. AJR Am J Roentgenol 1989;149:177-181

24. Bookstein JJ, Fellmath B, Roberts A, et al. Pulsed-spray pharmacomechanical thrombolysis: preliminary clinical results. AJR Am J Roentgenol 1989;152:1097-1100

25. Valji K, Bookstein JJ, Roberts AC, et al. Pharmacomechanical thrombolysis and angioplasty in the management of clotted hemodialyis grafts: early and late clinical results. Radiology 1991;178:243-247

26. Cynamon J, Lakritz PS, Wahl SI, et al. Hemodialysis graft declottin: description of the "lyse and wait" technique. J Vasc Interv Radiol 1997;8:825-829

27. Froehlich J, Stump DL. Recombinant tissue plasminogen activator. In: Camerota AJ, ed. Thrombolytic Therapy. Philadelphia, PA: JB Lippincott; 1995:103-114

28. Smalling RW. Molecular biology of plasminogen activators: what are the clinical implications of drug design? Am J Cardiol 1996;19:2-7

29. Van Ha T, Santeler SR, Lorenz JL, et al. Thrombolysis of dialysis access grafts: alteplase v. reteplase. J Vasc Interv Radiol 2002;13(suppl):536-537

30. Falk A, Mitty H, Guller J, Teodorescu V, Uribarri J, Vassalotti J. Thrombolysis of clotted hemodialysis grafts with tissue-type plasminogen activator. J Vasc Interv Radiol 2001; 12:305-311

31. Vogel P, Bansal V, Mashall M. Thrombosed hemodialysis grafts: lyse and wait with tissue plasminogen activator or urokinase compared to mechanical thrombolysis with the Arrow-Trerotola percutaneous thrombolytic device. J Vasc Interv Radiol 2001;12:1157-1165

32. Cooper SG. Pulse-spray thrombolysis of thrombosed hemodialysis grafts with tissue plasminogen activator. AJR Am J Roentgenol 2003;180:1063-1066

33. Falk A, Guller J, Nowakowski FS, et al. Reteplase in the treatment of thrombosed hemodialysis grafts. J Vasc Interv Radiol 2001;12:1257-1262 